\title{
Akut pankreatitli hastalarda, hastalığın şiddetini belirlemede bilgisayarlı tomografi ve modifiye bilgisayarlı tomografi şiddet indekslerinin karşılaştırılması
}

\author{
Comparison of CT severity index and modified CT severity index in patients with acute \\ pancreatitis, in determining the severity of the disease
}

İnci KIZILDAĞ YIRGIN, Elif HOCAOĞLU, Hakan YIRGIN, Arda KAYHAN, Nurten TURAN GÜNER, Serpil KALKAN GÖMEÇ, Sibel BAYRAMOĞLU, Tan CIMMILLİ

\section{ÖZET}

Amaç: Çalışmamızda, radyolojik skorlama sistemleri olan bilgisayarlı tomografi şiddet indeksi (BTŞI) ve modifiye bilgisayarlı tomografi şiddet indeksi (MBTŞİ)'nin pankreatitli hastalarda, hastalığın şiddet parametreleri ile korelasyonu, skorlama sistemlerinin biribirleri ile olan korelasyonu, ayrıca skorlama sistemleri ve Ranson kriterleri arasındaki korelasyon araştırılmıştır.

Hastalar ve Yöntem: Çalışmamızda 50 hasta retrospektif olarak incelenmiştir. Hastaların, demografik, klinik ve laboratuvar verileri kayıt edilmiştir. BT görüntülemede pankreas boyutları, peripankreatik planlarda inflamasyon bulguları, pararenal fasyada kalınlaşma, nekroz oranı, abse, lenfadenopati ve intraabdominal sıv1 araştırılmış ve bu verilere göre hastaların BTŞİ ve MBTŞİ değerleri hesaplanmıştır. Şiddet parametreleri, yaş, hastanede kalış süresi, abse, plevral sıvı ve ölüm olarak belirlenmiştir. Bilier ve non-bilier pankretit hastaları belirlenerek Ranson kriterleri hesaplanmıştır.

Bulgular: Her iki grupta, hafif, orta ve şiddetli alt grupların arasında, yaş ortalamaları, hastanede yatış süreleri, cinsiyet ve plevral sıvı varlığı açısından istatistiksel olarak anlamlı farklılık saptanmamış, ancak abse varlığı ve ölüm dağılımları arasında istatistiksel olarak anlamlı farklılık saptanmıştır. Her iki skorlama sistemindeki 3 alt grubun birbiri ile uyumunu belirlemek için ağırlıklı Kappa testi kullanılmış, ancak sonuçları uyumlu

İnci Kızıldağ Yırgın (ه)

Radyoloji Kliniği, Batman Bölge Devlet Hastahanesi, Batman, Türkiye e-mail: inci.kizildag@gmail.com

Elif Hocaoğlu, Nurten Turan Güner, Serpil Kalkan Gömeç, Sibel Bayramoğlu, Tan Cimilli

Radyoloji Kliniği, Bakırköy Dr Sadi Konuk Eğitim ve Araştırma Hastanesi, Istanbul, Türkiye

Hakan Yirgın

Genel Cerrahi Kliniği, Batman Bölge Devlet Hastahanesi, Batman,

Türkiye

Arda Kayhan

Radyoloji Anabilim Dall, Tip Fakültesi, Esenyurt Üniversitesi, İstanbul, Türkiye

Gönderilme/Submitted: 30.05 .2014

Kabul/Accepted: 17.09 .2014 bulunmamıştır. Ranson skorları ile BTŞİ ve MBTŞİ skorları arasında istatistiksel olarak anlamlı korelasyon gözlenmemiştir.

Sonuç: Çalışmamız göstermektedir ki, BTŞİ ve MBTŞİ'inde mortalite ve lokal komplikasyonlardan abse saptanma oranı ile, ve sadece MBTŞİ'inde ise, hastanede yatış süresi ile ilgili anlamlı korelasyon vardır. Her iki şiddet indeksinin biribirleri ile ve Ranson skoru ile korelasyon saptanmamıştır.

Anahtar Kelimeler: Akut pankreatit, BTŞİ, MBTŞİ

\begin{abstract}
Objective: In our study, the correlation between computed tomography severity index (CTSI) and modified computed tomography severity index (MCTSI) regarding assessment of severity parameters in acute pancreatitis, and Ranson criteria were investigated.
\end{abstract}

Patients and Methods: The study was retrospective and included 50 patients. Demographic, clinical and laboratory data were recorded. The size of the pancreas, peripancreatic inflammation, pararenal fascia thickening, necrosis, abscess, lymphadenopathy and abdominal ascites were investigated by computed tomography (CT) imaging. According to the data obtained, the CTSI and MCTSI values of each patient were calculated. The severity parameters of the disease; age, duration of hospitalization, abscess, pleural effusion and death were determined. Biliary, non-biliary pancreatitis and Ranson criteria were calculated.

Results: In both groups and subgroups (mild, moderate and severe), there were no significant differences regarding age, hospital stay, gender and pleural effusion. but significant differences were detected for the presence of abscess and distribution of death. To determine compliance with each three subgroups in both scoring systems, Kappa test was used but the results were not consistent. No statistically significant correlation was observed between CTSI and MCTSI and Ranson scores.

Conclusion: Our study shows that the CTSI and MCTSI are significantly correlated with mortality and abscess detection rate, only MCTSI is significantly correlated with the duration of hospitalization. Both of the severity indexes are not correlated with each other and Ranson Score.

Keywords: Acute pancretitis, CTSI, MCTSI 


\section{Giriş}

Akut pankreatit genellikle pankreasta hücresel hasar ve inflamasyonun eşlik ettiği, hafif ve kendini sınırlayan bir hastalıktır. Hastalığa organ disfonksiyonu da eşlik edebilir. Hafif, interstisyel-ödematoz form ve şiddetli akut nekrotizan form arasında geniş bir spektrum gösterdiğinden tedavisi de hastalığın şiddetine göre belirlenir. Hastaların \%80'i hafif ödematoz pankreatit geçirirken, \%10-20 hasta lokal ve sistemik komplikasyonlar ile multiorgan yetmezliği ve pankreatik nekrozun eşlik ettiği şiddetli pankreatit geçirmektedir [1]. Mortalite oranları ise hafif ödematoz formda $\% 3$ iken, akut nekrotizan formda $\% 15$ olarak belirlenmiştir [2]. Nekrozun erken tanınması hastalığın şiddetini ve prognozunu belirlemek açısından oldukça önemlidir.

Şiddetli akut pankreatitin erken tanınmasında kullanılan klinik, laboratuvar ve radyolojik kriterler içeren birçok skorlama sistemi bulunmaktadir. Ranson kriterleri, APACHE II ve III skorlama sistemi ve Balthazar bilgisayarlı tomografi şiddet indeksi (BTŞI) en sık kullanılanlar arasındadır. Balthazar ve arkadaşları tarafından 1990 yılında tanımlanan BTŞİ, sıvı koleksiyonu, pankreatik ve ekstrapankreatik inflamasyon ve nekroz oranı ile korele olup en yaygın kabul gören skorlama sistemidir [3]. Mortele ve arkadaşları tarafından 2004 yılında, modifiye bilgisayarlı tomografi şiddet indeksi (MBTŞì) tanımlanmıştır [4].

Biz bu çalışmada, radyolojik skorlama sistemleri olan BTŞİ ve MBTŞİ‘nin, pankreatitli hastalarda, hastalığın şiddet parametreleri ile korelasyonunu, her iki skorlama sisteminin biribirleri ile olan korelasyonunu ve ek olarak skorlama sistemlerinin Ranson kriterleri arasındaki korelasyonunu araştırdık.

\section{Hastalar ve Yöntem}

\section{Hastalar}

Çalışmaya 50 hasta (ortalama yaş: 51 , yaş aralığı 19-78) retrospektif olarak dahil edildi. Hastaların 28'i erkek (ortalama yaş: 53, yaş aralığı 23-78), 22'si kadın (ortalama yaş: 52.3 , yaş aralığı 19-78) idi. Akut pankreatiti olan 50 hastanın demografik, klinik ve laboratuvar verileri kayıt edildi. Çalışmamızın etik kurul onayı hastanemiz Etik Kurulu'ndan alınmıştır.

\section{Görüntüleme Tekniği}

Bilgisayarlı tomografi görüntüleme 40 sıralı multidedektör bilgisayarlı tomografi (MDBT) (Somatom Volume Zoom, Siemens) cihazı ile aşağıdaki parametreler kullanılarak yapıldı; kesit kalınlığı: 5 mm, 120 kv, 220 mAs. Hastaların tümüne bifazik kontrastlı BT yapılmıştır.
Tablo-I: BT şiddet indeksi (BTŞİ) ve modifiye BT şiddet indeksi (MBTşi).

\begin{tabular}{lcc}
\hline & BTŞİ (0-10) & MBTŞi (0-10) \\
\hline Pankreatik özellikler & 0 & 0 \\
Normal pankreas & 1 & 2 \\
Fokal veya diffüz büyüme & 2 & 2 \\
Peripankreatik inflamasyon & 3 & 4 \\
Tek sivi koleksiyonu & 4 & 4 \\
2 veya daha fazla sivı koleksiyonu & & \\
Pankreatik parankimal nekroz & 0 & 0 \\
Yok & 2 & 2 \\
$<\% 30$ & 4 & 4 \\
\%30-50 & 6 & 4 \\
>\%50 & 0 & 2 \\
Ekstrapankreatik & & \\
komplikasyonlar & & \\
\hline
\end{tabular}

Tablo-II: BTŞİ ve klinik şiddet parametrelerinin istatistiksel değerlendirmesi.

\begin{tabular}{|c|c|c|c|c|c|c|c|}
\hline BTşİ & & & Hafif n:42 & & Orta $n: 5$ & Şiddetli n:3 & $\mathbf{p}$ \\
\hline & Ort \pm SS & & $53,5 \pm 13,9$ & & $41,6 \pm 14,55$ & $61 \pm 11,79$ & \\
\hline \multirow[t]{2}{*}{ Yaş } & $\begin{array}{l}\text { Median } \\
\text { (Min-Max }\end{array}$ & \multicolumn{3}{|c|}{55,5 (19-78) } & $49(23-55)$ & $64(48-71)$ & \multirow[t]{2}{*}{0,124} \\
\hline & Ort $\pm \mathrm{SS}$ & \multicolumn{3}{|c|}{$6,8 \pm 7,66$} & $10,2 \pm 6,26$ & $20 \pm 18,25$ & \\
\hline $\begin{array}{l}\text { Yatış } \\
\text { Süresi }\end{array}$ & \multicolumn{2}{|c|}{$\begin{array}{l}\text { Median } \\
\text { (Min-Max) }\end{array}$} & \multicolumn{2}{|l|}{$3(1-38)$} & $8(2-17)$ & $11(8-41)$ & 0,080 \\
\hline BTşİ & & & Hafif & & Orta & Şiddetli & p \\
\hline \multirow{2}{*}{ Cinsiyet } & Erkek & 22 & $52,40 \%$ & 3 & $60,00 \%$ & $100,00 \%$ & \multirow{2}{*}{0,271} \\
\hline & Kadın & 20 & $47,60 \%$ & 2 & $40,00 \%$ & $0,00 \%$ & \\
\hline \multirow{2}{*}{ Abse } & Yok & 42 & $100,00 \%$ & 3 & $60,00 \%$ & $0,00 \%$ & \multirow{2}{*}{0,0001} \\
\hline & Var & 0 & $0,00 \%$ & 2 & $40,00 \%$ & $100,00 \%$ & \\
\hline \multirow{2}{*}{$\begin{array}{l}\text { Plevral } \\
\text { Sivi }\end{array}$} & Yok & 36 & $85,70 \%$ & 3 & $60,00 \%$ & $100,00 \%$ & \multirow{2}{*}{0,246} \\
\hline & Var & 6 & $14,30 \%$ & 2 & $40,00 \%$ & $0,00 \%$ & \\
\hline \multirow{2}{*}{ Kayıр } & Yaşıyor & 41 & $97,60 \%$ & 5 & $100,00 \%$ & $33,30 \%$ & \multirow{2}{*}{0,0001} \\
\hline & Kayıр & 1 & $2,40 \%$ & 0 & $0,00 \%$ & $66,70 \%$ & \\
\hline
\end{tabular}

IV kontrast madde otomatik enjektör ile $3 \mathrm{ml} / \mathrm{s}$ hızında, 100 ml kullanılmıştır.

$\mathrm{Bu}$ çalışmamızda, pankreas boyutları, peripankreatik yağlı planlarda inflamasyon bulguları, pararenal fasyada kalınlaşma, nekroz varlığı/oranı, abse, lenfadenopati varlığ1 ve intraabdominal sıvı araştırılmış ve bu verilere göre her hastanın BTŞİ ve MBTŞİ değerleri hesaplanmıştır (Tablo-I). Her iki skorlama sistemine göre 3 kategori bulunmaktadır; BTŞİ skorlama sistemine göre hafif (0-3), orta (4-6) ve şiddetli (7-10), MBTşİ skorlama sistemine göre ise hafif 
Tablo-III: MBTŞİ ve klinik şiddet parametrelerinin istatistiksel değerlendirmesi.

\begin{tabular}{|c|c|c|c|c|c|c|c|c|}
\hline MBTşi & & & Hafif n:15 & & Orta n:29 & & Şiddetli n:6 & $\mathbf{p}$ \\
\hline \multirow[b]{2}{*}{ Yaş } & Ort $\pm \mathrm{SS}$ & & $3,27 \pm 13,599$ & & $3,68 \pm 14,048$ & & $48 \pm 17,263$ & \multirow[b]{2}{*}{0,659} \\
\hline & $\begin{array}{l}\text { Median } \\
\text { (Min-Max) }\end{array}$ & & $55(30-78)$ & & $5,5(19-78)$ & & $49(23-71)$ & \\
\hline \multirow{2}{*}{$\begin{array}{l}\text { Yatış } \\
\text { Süresi }\end{array}$} & Ort \pm SS & & $5,57 \pm 9,53$ & & $7,46 \pm 6,49$ & & $4,71 \pm 12,672$ & \multirow[b]{2}{*}{0,048} \\
\hline & $\begin{array}{l}\text { Median } \\
\text { (Min-Max) }\end{array}$ & & $3(1-38)$ & & $5,5(1-21)$ & & $11(2-41)$ & \\
\hline \multicolumn{2}{|l|}{ MBTŞİ } & & Hafif & & Orta & \multicolumn{2}{|r|}{ Şiddetli } & $\mathbf{p}$ \\
\hline \multirow{2}{*}{ Cinsiyet } & Erkek & 10 & $66,70 \%$ & 12 & $42,90 \%$ & 6 & $85,70 \%$ & \multirow{2}{*}{0,076} \\
\hline & Kadın & 5 & $33,30 \%$ & 16 & $57,10 \%$ & 1 & $14,30 \%$ & \\
\hline \multirow{2}{*}{ Abse } & Yok & 15 & $100,00 \%$ & 28 & $100,00 \%$ & 2 & $28,60 \%$ & \multirow{2}{*}{0,0001} \\
\hline & Var & 0 & $0,00 \%$ & 0 & $0,00 \%$ & 5 & $71,40 \%$ & \\
\hline \multirow{2}{*}{$\begin{array}{l}\text { Plevral } \\
\text { Sivı }\end{array}$} & Yok & 15 & $100,00 \%$ & 21 & $75,00 \%$ & 6 & $85,70 \%$ & \multirow{2}{*}{0,102} \\
\hline & Var & 0 & $0,00 \%$ & 7 & $25,00 \%$ & 1 & $14,30 \%$ & \\
\hline \multirow{2}{*}{ Kayıр } & Yaşııor & 15 & $100,00 \%$ & 27 & $96,40 \%$ & 5 & $71,40 \%$ & \multirow{2}{*}{0,023} \\
\hline & Кауıр & 0 & $0,00 \%$ & 1 & $3,60 \%$ & 2 & $28,60 \%$ & \\
\hline
\end{tabular}

Tablo-IV: Her iki gruptaki hasta dağılımları.

\begin{tabular}{|c|c|c|c|c|c|c|}
\hline \multirow{2}{*}{$\begin{array}{l}\text { Şiddet } \\
\text { Parametreleri }\end{array}$} & \multicolumn{3}{|c|}{ BTŞİ } & \multicolumn{3}{|c|}{ MBTŞİ } \\
\hline & $\begin{array}{c}\text { Hafif } \\
(0-3) \\
n: 42\end{array}$ & $\begin{array}{c}\text { Orta } \\
(4-6) \\
n: 5\end{array}$ & $\begin{array}{c}\text { Şiddetli } \\
(7-10) \\
\text { n:3 }\end{array}$ & $\begin{array}{c}\text { Hafif } \\
(0-2) \\
n: 15\end{array}$ & $\begin{array}{l}\text { Orta } \\
(3-6) \\
n: 29\end{array}$ & $\begin{array}{c}\text { Şiddetli } \\
(8-10) \\
\text { n:6 }\end{array}$ \\
\hline $\begin{array}{l}\text { Hastanede kalış } \\
\text { süresi (gün) }\end{array}$ & $\begin{array}{c}6.7 \\
(3-38)\end{array}$ & $\begin{array}{c}10.2 \\
(8-17)\end{array}$ & $\begin{array}{c}20 \\
(8-41)\end{array}$ & $\begin{array}{c}5.4 \\
(1-38)\end{array}$ & $\begin{array}{c}7.4 \\
(1-21)\end{array}$ & $\begin{array}{c}14.5 \\
(2-41)\end{array}$ \\
\hline Abse (h.sayısı) & $\mathrm{n}: 0$ & $\mathrm{n}: 2$ & $\mathrm{n}: 3$ & $\mathrm{n}: 0$ & $\mathrm{n}: 0$ & $\mathrm{n}: 4$ \\
\hline $\begin{array}{l}\text { Plevral sıvı } \\
\text { (h. sayısı) }\end{array}$ & $\mathrm{n}: 6$ & $\mathrm{n}: 2$ & $\mathrm{n}: 0$ & $\mathrm{n}: 0$ & $\mathrm{n}: 7$ & $\mathrm{n}: 1$ \\
\hline Ölüm (h.sayısı) & $\mathrm{n}: 1$ & $\mathrm{n}: 0$ & $\mathrm{n}: 2$ & $\mathrm{n}: 0$ & $\mathrm{n}: 1$ & $\mathrm{n}: 2$ \\
\hline
\end{tabular}

Tablo-V: Ranson ve görüntüleme indekslerinin korelasyonu.

\begin{tabular}{lcc}
\hline & & Ranson Skoru \\
\hline \multirow{2}{*}{ BTşì } & $\mathbf{r}$ & $-0,034$ \\
\multirow{2}{*}{ MBTşi } & $\mathbf{p}$ & 0,813 \\
& $\mathbf{r}$ & $-0,049$ \\
& $\mathbf{p}$ & 0,733 \\
\hline
\end{tabular}

(0-2), orta (4-6), şiddetli (8-10) olarak belirlenmiştir. Hastalığın şiddet parametreleri yaş, hastanede kalış süresi, abse, plevral sıvı ve ölüm olarak belirlenmiştir. Bilier ve non-bilier pankretit hastaları da belirlenerek Ranson kriterleri ayrı ayrı hesaplanmıştır.

\section{İstatistiksel Analiz}

$\mathrm{Bu}$ çalışmada, istatistiksel analizler NCSS (Number Cruncher Statistical System) 2007 Statistical Software (Utah, USA) paket programı ile yapılmıştır. Verilerin değerlendirilmesinde tanımlayıcı istatistiksel metotların (ortalama, standart sapma, median, sayısal aralık) yanı sıra, gruplar arası karşılaştırmalarda Kruskal Wallis testi, alt grup karşılaştırmalarında Dunn's çoklu karşılaştırma testi, nitel verilerin karşılaştırmalarında ki-kare testi kullanılmıştır. BTŞI ve MBTŞİ uyumunu belirlemek için ağırlıklı Kappa testi kullanılmıştır. Değişkenlerin biribirleri ile ilişilerini belirlemede Spearman korelasyon testi kullanılmıştır. Sonuçlar, anlamlılık $\mathrm{p}<0,05$ düzeyinde değerlendirilmiştir.

\section{Bulgular}

Bilgisayarlı tomografi şiddet indeksine göre 50 hastanın 42 'si (\% 84) hafif, 5’i (\% 10) orta, 3 'ü (\% 6) şiddetli grupta, MBTŞI'ye göre ise hastaların 15 'i (\% 30) hafif, 29 'u (\% 58) orta , 6 's1 (\%12) ise şiddetli grupta sinıflandı.

Hastalığın klinik şiddet parametreleri ve BTŞİ skorlama sistemi arasındaki korelasyon sonuçlarına göre (Tablo-II); hafif, orta ve şiddetli grupların arasında yaş ortalamaları, yatış süreleri, cinsiyet dağılımları ve plevral sıvı varlığı açısından istatistiksel olarak anlamlı farklılık gözlenmemiştir. BTŞİ'ne göre bu üç grubun abse varlı̆̆ 1 ve ölüm dağılımları arasında istatistiksel olarak anlamlı farklılık gözlenmiştir. Hafif grupta hiç abse gözlenmemiştir. Şiddetli grupta ise ölüm oranı yüksek bulunmuştur.

Hastalığın klinik şiddet parametreleri ve MBTşi skorlama sistemi arasındaki korelasyon sonuçlarına göre (Tablo-III); hafif, orta ve şiddetli gruplarının arasında yaş ortalamaları, cinsiyet dağılımları, plevral sıvı varlığ açısından istatistiksel olarak anlamlı farklılık gözlenmemiştir. MBTŞI'ne göre hafif, orta ve şiddetli gruplarının yatış süresi ortalamaları incelendiğinde ise istatistiksel olarak anlamlı farklılık gözlenmiştir $(\mathrm{p}=0,048)$. Hafif grubunun yatış süresi orta ve şiddetli gruplarının yatış süresi ortalamalarından istatistiksel olarak anlamlı derecede düşük bulunup ( $\mathrm{p}=0,044, \mathrm{p}=0,011)$, diğer gruplar arasında istatistiksel olarak anlamalı farklılık gözlenmemiştir (p>0,05). MBTŞİ'ne göre bu grupların abse ve ölüm dağılımları arasında da istatistiksel olarak anlamlı farklılık gözlenmiştir. Şiddetli grubunda abse ve ölüm oranı anlamlı olarak yüksek bulunmuştur.

Her iki skorlama sistemindeki 3 alt grubun birbiriyle uyumunu belirlemek için ağırlıklı Kappa testi kullanılmıştır. BTŞİ ve MBTŞİ sonuçları uyumlu bulunmamıştır $\left(\kappa_{\mathrm{w}}: 0,093 \mathrm{p}=0,135\right)$. 
Hastaların, Ranson skorlama sistemine göre sinıflandirılmasında ise; 47 (\%94) hasta Ranson 0-1-2 kriter, 2 (\%4) hasta Ranson 3 kriter, 1 (\%1) hasta ise Ranson 5 kriter olarak değerlendirilmiştir. BT skorlama sistemlerinin Ranson ile korelasyonu araştırıldı̆̆ında; Ranson skorları ile BTŞİ ve MBTŞİ skorları arasında istatistiksel olarak anlamlı korelasyon gözlenmemiştir ( $\mathrm{r}=$ $0,034 \mathrm{p}=0,813, \mathrm{r}=-0,049 \mathrm{p}=0,733$ ) (Tablo-V).

\section{Tartışma}

Bilgisayarlı tomografi şiddet indeksi, akut pankreatitin erken döneminde BT görüntülemenin tanıya olan katkısını arttırmaktadır [3,5]. Bu dönemde pankreatik nekrozun gelişmesi ve nekrozun yaygınlığı hastalığın şiddetini belirlemede en önemli parametrelerden biridir [6-10]. BTŞI arttıkça mortalite oranı artmaktadır. Índeksi 0-2 olan hastada mortalite oran $1 \% 0$ iken indeksi 7-10 arasında olan hastalarda mortalite oran $1 \% 17$ olarak kabul edilmektedir [3].

Biz çalışmamızda, genel olarak kabul görmüş BTŞİ ile, kullanıma sonradan girmiş olan MBTŞİ mortalite ve diğer klinik şiddet parametreleriyle korelasyonunu araştırdık. Her iki grupta da yaş, cinsiyet dağılımları ve plevral sıvı varlığı açısından hafif-orta ve şiddetli gruplarda fark saptanmaması, radyolojik skorlama sistemlerinin sistemik komplikasyonlardan ziyade lokal komplikasyonlar ile daha fazla korele olmasıyla açıklanabilir [11].

Diğer şiddet parametrelerinden hastanede yatış süresi korelasyon sonuçlarımızı daha önce yapılan çalışmalar ile karşılaştırdığımızda uyumlu sonuçlar elde ettiğimiz görülmektedir. Örneğin Mortele ve arkadaşlarının 2004 yılında yaptıkları bir çalışmada hastanede kalış süresi açısından MBTŞİ ile BTŞİ karşılaştırılmış ve bizim çalışmamızda olduğu gibi MBTŞİ ile daha iyi bir korelasyon olduğu saptanmıştır [4].

Her iki skorlama sisteminin mortalite ile olan ilişkisi literatürde tartışmalı konulardan biridir. 1990 yılında Balthazar ve arkadaşları BTŞİ'ni mortalite ile çok iyi korelasyon gösteren bir yöntem olarak tanımlamışlardır [3]. $\mathrm{Bu}$ görüşü destekleyen birçok çalışma bulunmaktadır [1214]. Ancak, De Waele ve arkadaşlarının 2007 yılında yaptıkları çalışmada BTŞİ ile mortalite arasında korelasyon saptanmamıştır [15]. Bizim çalışmamız da, literatürdeki birçok çalışma ile uyumlu olarak BTŞİ ve MBTŞİ ile mortalite arasında anlamlı korelasyon bulunmuştur.

Lokal komplikasyon oranlarının, BTŞİ ile şiddetli korelasyon gösterdiği birçok çalışma ile kanıtlanmıştır [14,16,17]. Yaptığımız çalışmada, lokal komplikasyonlardan biri olan abse saptanma oranı hem BTŞİ hem de MBTŞİ ile anlamlı korelasyon göstermektedir.
Çalışmamıza göre BTŞİ ve MBTŞİ‘nin hastalığın şiddet parametreleriyle ayrı ayrı incelendiğinde anlamlı korelasyon göstermesine rağmen, her iki şiddet indeksinin biribiri ile uygunluk göstermemesinin hafif, orta ve şiddetli gruptaki hasta sayılarına bağlı olduğu düşünülmüştür. Skorlama sisteminde BTŞİ'de 1 puan alan "fokal veya diffüz büyüme gösteren pankreas" kriterinin, MBTŞI'de 2 puan alması ve BTŞI'‘ne göre birçok hastamızın da bu grupta bulunuyor olmasının istatistiksel sonuçlara yansıdığını düşünmekteyiz.

$\mathrm{Bu}$ korelasyon açısından literatür değerlendirildiğinde başta Thomas ve arkadaşları [11] olmak üzere birkaç çalışmada her iki şiddet indeksinin birbiri ile korele olduğu görüşü mevcuttur.

Her iki görüntüleme şiddet indeksi ve Ranson kriterleri arasında anlamlı korelasyon bulunmaması hastaların Ranson dağılımlarındaki farklılıktan kaynaklanıyor olabilir.

Çalışmamızın bazı limitasyonları mevcuttu. Bunlardan birisi hasta sayımızın yetersiz olması, diğeri ise çalışmamızın retrospektif olması idi.

Sonuç olarak, çalışmamız göstermektedir ki, BTŞİ ve MBTŞİ mortalite ve lokal komplikasyonlardan abse saptanma oranı ile, sadece MBTŞI'ine göre ise hastanede yatış süresi anlamlı korelasyon göstermektedir. Her iki şiddet indeksinin birbiri ile ve Ranson skoru ile korelasyonu saptanmamıştır.

\section{Kaynaklar}

1. Forsmark CE, Baillie J. AGA Institute technical review on acute pancreatitis. Gastroenterology 2007; 132:2022-44. doi:10.1053/j.gastro.2007.03.065

2. Van Santvoort HC, Bakker OJ, Bollen TL, et al. A conservative and minimally invasive approach to necrotizing pancreatitis improves outcome. Gastroenterology 2011;141:1254-63. doi:10.1053/j.gastro.2011.06.073

3. Balthazar EJ, Robinson DL, Megibow AJ, Ranson JH. Acute pancreatitis: value of CT in establishing prognosis. Radiology $1990 ; 174: 331-6$. doi:10.1148/ radiology.174.2.2296641

4. Mortele KJ, Wiesner W, Intriere L, et al. A modified CT severity index for evaluating acute pancreatitis:improved correlation with patient outcome.AJR Am J Roentgenol 2004; 183:1261-5.

5. Balthazar EJ, Freeny PC, vanSonnenberg E.Imaging and intervention in acute pancreatitis. Radiology 1994; 193:297306.

6. Bradley EL III. A clinically based classification system for acute pancreatitis. ArchSurg 1993;128:586-90. doi:10.1001/ archsurg.1993.0142017012 2019.

7. Dervenis C, Johnson CD, Bassi C, et al. Diagnosis, objective assessment of severity, and management of acute pancreatitis. Int J Pancreatol 1999; 25:195-210.

8. Banks PA. Acute pancreatitis: medical and surgical management. Am J Gastroenterol 1994; 89:S78-S85. 
9. Banks PA. Practice guidelines in acute pancreatitis. Am J Gastroenterol 1997; 92: 377-86.

10. Beger HG, Rau B, Mayer J, Pralle U. Natural course of acute pancreatitis. World J Surg 1997; 21:130-5.

11. Bollen TL, Singh VK, Maurer R, et al. Comparative evaluation of the modified CT severity index and CT severity index in assessing severity of acute pancreatitis. AJR Am J Roentgenol 2011; 197:386-92. doi: 10.2214/AJR.09.4025

12. Leung TK, Lee CM, Lin SY, et al. Balthazar computed tomography severity index is superior to Ranson criteria and APACHE II scoring system in predicting acute pancreatitis outcome. World J Gastroenterol 2005; 11:6049-52

13. Simchuk EJ, Traverso LW, Nukui Y, Kozarek RA. Computed tomography severity index is a predictor of outcomes for severe pancreatitis. Am J Surg 2000; 179:352-5.
14. Vriens PW, van de Linde P, Slotema ET, Warmerdam PE, Breslau PJ. Computed tomography severity index is an early prognostic tool for acute pancreatitis. J Am Coll Surg 2005; 201:497-502. doi:10.1016/i.jamcollsurg.2005.06.269

15. De Waele JJ, Delrue L, Hoste EA, et al. Extrapancreatic inflammation on abdominal computed tomography as an early predictor of disease severity in acute pancreatitis: evaluation of a new scoring system. Pancreas 2007; 34:185-90.

16. Triantopoulou C, Lytras D, Maniatis P, et al. Computed tomography versus Acute Physiology and Chronic Health Evaluation II score in predicting severity of acute pancreatitis. Pancreas 2007;35:238-2.

17. De Sanctis JT, Lee MJ, Gazelle GS, et al. Prognostic indicators in acute pancreatitis: CT vs APACHE II. Clin Radiol 1997; 52:842-8. 